\title{
The uses of some as determiner in BSAfE
}

\author{
Yolande Botha \\ North-West University, South Africa \\ E-mail: Lande.Botha@nwu.ac.za
}

\begin{abstract}
The determiner some is used primarily as an indication of an unspecified, but particular quantity. The question of whether this core meaning of some is extended in Black South African English (BSAfE) is addressed in this paper. In an intercorpus comparison, it is found (unexpectedly) that the determiner some occurs significantly less frequently in the BSAfE corpus than in the Indian English corpus. However, it is also found that the determiner some precedes plural nouns significantly more frequently in BSAfE than in Indian English. Similar differences are not observed in a comparison of BSAfE with a Kenyan English corpus. In the BSAfE intracorpus investigation, a collexeme analysis indicates a strong collocational attraction between the determiner some and a number of plural nouns. A co-varying collexeme analysis among all possible determiners and five frequently occurring non-singular nouns provides further confirmation of the strong association between some and plural nouns.
\end{abstract}

Keywords: Black South African English, determiner, quantifier

\section{Introduction}

Observations of the notable uses of determinative some in Black South African English (BSAfE) focus on the use of some with the quantifier few. Van der Walt and Van Rooy (2002: 124) report a $72 \%$ acceptance rate of the expression some few among BSAfE learners. De Klerk (2003a: 232) reports 10 instances of some few in her corpus of over 540000 words of spoken Xhosa English, although she notes 43 instances overall "in which some was used inappropriately" (De Klerk 2003b: 470), which include instances where some is used with non-pluralised forms of countable nouns. These "inappropriate" uses of some are grouped with expressions like too much (meaning 'very much') under the heading "overgeneralisation of quantifiers" (De Klerk 2003b: 470). Minow (2010: 63) reports only two instances of some few in her database of 85431 words of spoken BSAfE. She provides the following example:

(1) I think like some few weeks ago, (.) they had a official opening of one of the bars, (...) so. (BSAEF06) (Minow 2010: 63).

The use of some few instead of a few is regarded as a feature of New Englishes in general. Platt, Weber and Ho (1984: 60) attribute this to the strong association that few has with 
plurality, remarking that "[t]he use of $a$ seems incompatible with few and couple which are associated with the plural".

(2) You are expected to say some few words (from Sri Lankan English) (Platt et al. 1984: 60)

(3) Some few minutes past nine I leave the office (from West African English) (Platt et al. 1984: 60)

A concordance comparison of some in BSAfE student writing (Tswana Learner English Corpus) and native English student writing (Louvain Corpus of Native English Essay) ${ }^{1}$ suggests that the non-proportional meaning of some as determiner is extended to contexts in which it would not be used in Standard English (Botha 2012, 2013). In many of these cases the agnate standard expression would have no determiner, as illustrated in the example below.

(4) the goverment would be losing some sums of money to not so committed soccer players. <ICLE-TS-NOUN-0386.1> (Botha 2012)

It is argued that some is used like the non-singular counterpart of alan instead of the zero determiner with plural nouns to explicitly mark the noun phrase as indefinite in BSAfE student writing (Botha 2013). This use of some as a kind of plural indefinite "article" is interpreted as further evidence of the anti-deleting trend that Mesthrie (2006) identifies as characteristic of BSAfE grammar in general. The "article" function of some is especially noticeable in collocations with postdeterminers and quantifiers. As can be seen in the following examples from the Tswana Learner English Corpus:

(5) In some certain circumstances, men ill-treat women. <ICLE-TS-NOUN-0501.1>

(6) They go to some severals areas including towns where they becomes the prostitudes $<$ ICLE-TS-NOUN-0172.1>

From a prescriptive perspective the use of some in the examples above will be regarded as non-standard since some is generally treated as an existential quantifier (e.g. Payne and Huddleston 2002: 358). However, in examples (5) and (6) the quantificational meaning of some is secondary to its indefinite meaning in much the same way as the quantificational meaning of a/an has become secondary to its indefinite meaning in the process of the grammaticalisation of the word one (Botha 2012, 2013). In Standard English reformulations of the noun phrases underlined in examples (5) and (6) above, the zero article would be preferred (viz. certain circumstances and several areas, respectively). Singulative reformulations would be a certain circumstance and one area, respectively.

It is proposed here that many of the so-called "non-standard" uses of some in BSAfE can be explained in terms of the application of a noun phrase template with an overt (in)definiteness marker (i.e. article). The article-like use of some can be seen as a "nativized semanticostructural analogy" (Mukherjee 2010, Mukherjee and Hoffman 2006). In these cases the use of some with plural nouns is analogous to the obligatory use of alan with (countable) indefinite singular nouns.

\footnotetext{
${ }^{1}$ Both these corpora are part of the International Corpus of Learner English (Granger, Dagneaux, Meunier and Paquot 2009).
} 
The possibility that the determiner some is used to fulfil a more article-like function in BSAfE will be investigated with reference to larger corpus data sets. Given the observations of some few and some couple of in other New Englishes (Platt et al. 1984: 60), a quantitative comparison of the use of some in three corpora representing New Englishes was conducted. To establish whether the proposed article-like use of some with plural nouns observed in BSAfE student writing by Botha (2013) can also be attested in other text types, the choice of some as determiner was examined in a BSAfE corpus that allows for comparison of student writing with professional writing (both academic and journalistic) and conversation. It is possible that features in student writing as part of the learning process are not retained in more advanced written registers. Therefore, grammatical features attested in professional and academic writing are a more accurate indication of stabilisation in the variety.

The quantitative investigation aims to highlight the larger context of the uses of some whereas the qualitative examination of concordance examples aims to establish whether the function of some as a plural counterpart of the indefinite article alan adequately explains the uses of some in BSAfE that have hitherto simply been regarded as deviations from the native English norm. However, it is not suggested that the pattern some $\mathbf{N}_{\text {plural }}$ is preferred over $\boldsymbol{\emptyset} \mathbf{N}_{\text {plural. }}$. It goes without saying that the article-like use with plural nouns is not the only way in which some is used in BSAfE and concordance analyses show that it is mostly used in the same ways as in native English.

\section{The meanings of determiner some}

Syntactically, the word some can function as a pronoun or a determiner. It is useful to distinguish two pronominal some-constructions - one where some is the logical head in a partitive of-construction, and one where some constitutes a one-word noun phrase functioning as clausal element. Semantically, the word some (regardless of its syntactic position) is usually regarded as a quantifier. Payne and Huddleston (2002: 358ff) follow the tradition of formal logic in treating some as an existential quantifier along with any, stating that some is the "most straightforward expression" of existential quantification and defining it as an indication of a quantity or number greater than zero. Payne and Huddleston (2002: 360) point out that with countable nouns, some "indicates not just a number greater than zero but a number no less than two" (my emphasis - YB).

Payne and Huddleston (2002: 364-365) further distinguish between the proportional and the non-proportional uses of some. When some implies 'not all' it has a proportional meaning, and if some does not activate a 'not all' implicature, it is interpreted non-proportionally.

(7) Some people misunderstood the question. [proportional] (Payne and Huddleston 2002: 364)

(8) I saw some children climb over the fence. [non-proportional] (Payne and Huddleston 2002: 364)

In (7), the speaker has a larger set in mind, but the $I$ in (8) does not have a larger set of children in mind - of which a proportion could be seen climbing over the fence. As the examples above illustrate, the non-proportional uses of some are only relevant to the determinative function of some. The pronominal uses of some have inherent proportional meaning in that they always activate the 'not all' implicature. 
While the distinction between the proportional and non-proportional senses of some is useful in describing its quantificational uses, Duffley and Larrivée (2012) argue that the determiner some can also have non-quantitative, i.e. qualitative, meanings that have not been adequately accounted for. The authors provide an extensive overview and critique of the treatment of some (i) in the logical tradition and (ii) in a model of scalar implicature. As logical quantifier some signifies a quantity of 'at least one, possibly more' and implies that the entity, or set of entities, is unidentified, while some as scalar attenuator is supposed to evoke a "less-thanexpected quantity on a pragmatic scale" (Duffley and Larrivée 2012: 132). Duffley and Larrivée (2012: 132) use the following examples to illustrate a qualitative sense of some that is not explained by the logical nor the scalar view of some:

(9) That was some frittata.

(10) He made some thirty-three snowmen that afternoon.

The frittata in question is identifiable (hence the use of the demonstrative that) and larger or better than expected. Thirty-three is an exact number, not an unidentified estimate, and although the logical criterion of 'at least one, possibly more' is met, it does not contribute to the definition of some. Again, a number greater, not less, than expected is at issue. In the latter example, the meaning of some is also qualitative. Duffley and Larrivée (2012) go on to propose an exposition of the meaning of some that can account for both its quantitative and qualitative senses. They argue that "a single underlying meaning, modulated by contextual and pragmatic factors, can give rise to the wide variety of messages expressed by some in actual usage" (Duffley and Larrivée 2012: 132-133). This single, underlying meaning of some evokes "a particular, but non-identified referent" (Duffley and Larrivée 2012: 143, my emphasis - YB). This non-identification of a particular referent can give rise to "qualitative denigration (implying it is not even worth the bother to identify the referent) or qualitative appreciation (implying the referent to be so outstanding it defies identification)" (Duffley and Larrivée 2012: 131). Qualitative denigration arising from nonidentification is illustrated in examples (11) and (12) below, while the example of some frittata in (9) above is illustrative of the use of some to express appreciation of exceptionality (cf. also Duffley and Larrivée 2012: 141-142).

(11) Some idiots must have tracked mud into the lobby (Duffley and Larrivée 2012: 137).

(12) He was looking for some brand of coffee from the Malabar coast (Duffley and Larrivée 2012: 137).

Duffley and Larrivée (2012: 139) point out that in combination with numerals, some can either convey 'approximation', which Payne and Huddleston (2002: 380) refer to as "considerable quantity". The example in (10) of some thirty-three snowmen illustrates the use of some to express qualitative appreciation of an identified, but exceptional, quantity. Approximative interpretations of some with numerals are associated more with round numbers, as shown in (13).

(13) There were some fifty villages that agreed to the plan (Duffley and Larrivée 2012: 139).

In (13), some characterises fifty as an approximate quantity. Stressed some can express both a small quantity and a rather large quantity (Duffley and Larrivée 2012: 139, Payne and Huddleston 2002: 140), as can be seen in (14) and (15): 
(14) I have some idea of what you mean, but it's still a bit hazy.

(15) It was some years before she saw him again.

In addition to stress (sentence accent), the grammatical number features of the noun determined by some can serve as a modulating factor in the interpretation of some (Duffley and Larrivée 2012: 142-143). For instance, the pejorative qualitative sense of some is typically associated with the singular form. Duffley and Larrivée (2012: 143) explain how the underlying meaning of some, namely "a particular, but non-identified referent" applies differently to singular and plural nouns. With singular nouns, some indicates that the referent itself is not identified. With plural and mass nouns, some indicates an unidentified quantity. Corpus instances of the determiner some with plural nouns in noun phrases that can be interpreted as non-proportional and/or as non-particular would indicate a potential extension of the core meaning of some to an article-like function.

\section{Corpora}

For the first part of the study, a corpus of BSAfE was compared with two corpora representing New Englishes. Like in Van Rooy $(2014)^{2}$, this study makes use of selected sections of the Indian and East-African (Kenyan) components of the International Corpus of English (ICE-IND and ICE-EA(K)) for which comparable BSAfE corpus data exist. Like BSAfE, Indian English and Kenyan English can be regarded as Outer Circle varieties in terms of Kachru's (1986) classification of the varieties of English. These Outer Circle varieties share some common characteristics, as already indicated by Platt et al. (1984). Van Rooy (2010: 14) contrasts a tendency among Outer Circle varieties to avoid morphologically marking of redundant features with the anti-deletion tendency of Black South African English mentioned by Mesthrie (2006). Where Outer Circle varieties generally tend to avoid marking of redundant features, one finds in BSAfE overt marking of syntactic relations not usually marked in other varieties of English. The article-like use of some in contexts where it would normally be omitted is regarded as further evidence of the anti-deletion tendency (Botha 2013). The expectation is that this use of some will not occur in other Outer Circle varieties, such as Kenyan English and Indian English.

Like BSAfE, Kenyan English and Indian English also represent institutionalised varieties of second-language English used by speakers possibly coming from different first language backgrounds in multilingual countries. The BSAfE corpus data represent various (but related) first-language (L1) backgrounds. The variety in L1 backgrounds (at least nine of the official languages), and differing levels of proficiency, have given rise to questions about the validity of the term "Black South African English" (De Klerk 2003b: 464). The nine L1s of speakers of BSAfE can be divided into four clusters, the largest of which are the Nguni (isiZulu, isiXhosa, isiNdebele, SiSwati) and Sotho-Tswana (Sesotho, Sesotho sa Leboa, Setswana) groups (Zerbian 2015). All of these languages are Southern Bantu languages and, as such, have much in common structurally. Makalela (2004) illustrates the role of Bantu language structure in features of BSAfE relating to the extension of progressive aspect, tense sequencing, topic promotion devices and modality markers, using examples from Sepedi (a Northern Sotho dialect). De Klerk (2003a,b) finds evidence for some of these features in her corpus of Spoken Xhosa English, specifically with regard to topic pronouns and the extension

\footnotetext{
${ }^{2}$ I wish to thank Bertus van Rooy for generously sharing the BSAfE corpus data and sample sets used in his research.
} 
of the progressive. These examples of similar grammatical features in BSAfE from speakers with differing L1 varieties suggest that it is not unreasonable to use BSAfE corpus data collected from speakers of differing L1 backgrounds when grammatical structures are studied. Van Rooy $(2008,2014)$, for instance, uses such data in studying aspect in BSAfE. In a study of focus marking in BSAfE, Zerbian (2015: 228) finds that differences in frequency of syntactic structures "cannot be accounted for solely by L1 influence", while prosodic differences "can be related to L1 influence". It should also be borne in mind that many speakers of BSAfE, are not only bilingual, but multilingual, fluently speaking more than one of the indigenous South African languages (Coetzee-Van Rooy 2012).

Table 1 gives a breakdown of the corpora with an indication of the relevant ICE subcomponents.

Table 1: Compilation of corpora

\begin{tabular}{|l|r|r|r|}
\hline & ICE-IND & $\begin{array}{r}\text { ICE- } \\
\text { EA(K) }\end{array}$ & BSAfE \\
\hline (Broadcast) interviews and discussions (S1B-021-050) & 74715 & 86732 & 47610 \\
\hline Conversation (S1A-001-090) & 193675 & 55419 & 113444 \\
\hline Class lessons (S1B-001-020) & 43797 & 27685 & 57709 \\
\hline Academic writing (W2A-001-040) & 84594 & 79134 & 48315 \\
\hline Student writing (W1A-001-020) & 40711 & 39766 & 200601 \\
\hline Journalism (W2C-001-020) & 39411 & 39538 & 42575 \\
\hline Fiction (W2F001-020) & 47572 & 40086 & 72904 \\
\hline TOTAL (raw frequency of tokens) & $\mathbf{5 2 4} 475$ & $\mathbf{3 6 8 ~ 3 6 0}$ & $\mathbf{5 8 3 ~ 1 5 8}$ \\
\hline
\end{tabular}

The data from ICE-IND corresponds with the ICE text codes given in Table 1, while ICEEA(K) deviates slightly from the standard composition of ICE corpora (Schmied 1990). The ICE-EA(K) class lessons range from S1B-001K to S1B-013K, while student writing goes up to W1A-021. ICE-EA(K) has less conversation samples than typical ICE corpora (S1A-001K to S1A-0017K and S1A-021K to S1A-030K). The Volkswagen corpus (in Meierkord 2012) constitutes the interview component of the BSAfE data. BSAfE student writing is represented by the Tswana Learner English Corpus, which was originally collected as part of the International Corpus of Learner English (ICLE) (Granger et al. 2009). The BSAfE conversation and class-lesson components consist of samples from De Klerk's (2003a) corpus of spoken Xhosa English. The journalism and fiction components of the BSAfE corpus consist of texts published in the 1990s-2000s collected by Van Rooy (2014). The raw word frequencies for the various corpora were obtained with the Wordlist function in Wordsmith 6.0 (Scott 2013), which allows for the exclusion of extralinguistic information (in the form of mark-up).

For the second part of the study, a smaller sampling of the abovementioned BSAfE corpus along with additional student essays were used and grouped to represent three text types, namely conversation, student writing and professional writing. The conversation component consists of a sample $(n=53)$ of conversations from De Klerk's (2003a) corpus of spoken Xhosa English and 12 interviews from the Volkswagen Corpus (Meierkord 2012), the student writing component consists of a smaller sample of the Tswana Learner English Corpus (81 of the 519 essays), and 60 student essays from Gauteng and 81 texts collected by Beth Jefferey in the Eastern Cape. The professional writing component consists of the 20 journalism texts 
used in the aforementioned BSAfE corpus, and 25 excerpts from academic theses (each approximately 1000 words in length). The breakdown of this corpus is given in Table 2.

Table 2: Compilation of BSAfE subcorpora

\begin{tabular}{|l|r|r|}
\hline BSAfE subcorpus & Number of texts & Number of tokens \\
\hline Conversation & 65 & 178825 \\
\hline Student writing & 222 & 87405 \\
\hline Professional writing & 45 & 68380 \\
\hline
\end{tabular}

\section{Distribution of some across three New Englishes corpora}

Concordances of some were drawn for every subcorpus. The determinative uses of some were then isolated from its pronominal uses. Table 3 provides the raw number of occurrences of some as determiner together with the normalised frequency of determinative some per 10000 words in the relevant corpus component.

Table 3: Frequencies of determinative some in three WE corpora

\begin{tabular}{|l|r|r|r|r|r|r|}
\hline \multirow{2}{*}{} & \multicolumn{3}{|c|}{ Raw frequencies } & \multicolumn{2}{c|}{$\begin{array}{r}\text { Relative frequencies per } \\
\text { 1000 words }\end{array}$} \\
\cline { 2 - 7 } & $\begin{array}{r}\text { ICE- } \\
\text { IND }\end{array}$ & $\begin{array}{r}\text { ICE- } \\
\text { EA(K) }\end{array}$ & $\begin{array}{r}\text { BSAf } \\
\text { E }\end{array}$ & $\begin{array}{r}\text { ICE- } \\
\text { IND }\end{array}$ & $\begin{array}{r}\text { ICE- } \\
\text { EA(K) }\end{array}$ & $\begin{array}{r}\text { BSAf } \\
\text { E }\end{array}$ \\
\hline Broadcast interviews and discussions & 149 & 172 & 69 & 19.9 & 19.8 & 14.5 \\
\hline Conversation & 507 & 95 & 162 & 26.2 & 17.1 & 14.3 \\
\hline Classroom lessons & 50 & 31 & 42 & 1.4 & 11.2 & 7.3 \\
\hline Academic writing & 82 & 113 & 50 & 9.7 & 14.3 & 10.3 \\
\hline Student writing & 74 & 93 & 514 & 18.2 & 23.4 & 25.6 \\
\hline Journalism & 37 & 40 & 25 & 9.4 & 10.1 & 5.9 \\
\hline Fiction & 44 & 55 & 96 & 9.2 & 13.7 & 13.2 \\
\hline TOTAL & 943 & 599 & 958 & 18.0 & 16.3 & 16.4 \\
\hline
\end{tabular}

The relative frequencies in Table 3 show that there is some variability across the corpora within registers. Most notable is the lower frequency of determinative some in the spoken BSAfE registers. Contingency tables (Chi-square, Fisher Exact, Log likelihood tests) were used to compare the total raw frequencies of determinative some in relation to the total number of all other tokens in two corpora at a time. The difference in the observed frequencies of determinative some in the BSAfE and ICE-EA(K) corpora is not statistically significant $(\mathrm{p}>0.8)$, whereas both the BSAfE corpus and the Kenyan English corpus differ significantly from the Indian English corpus in this respect $(\mathrm{p} \leq 0.05)$. The significantly lower frequency of determinative some in the BSAfE corpus compared to the Indian English corpus seems to disprove the hypothesis that some is used as an (undeleted) indefinite marker in BSAfE, whereas a higher frequency of determinative some in BSAfE would have supported the notion of the extended usage of some to article-like functions in this variety.

The next step was to categorise all instances of determinative some according to the number features of the head noun of the noun phrase in which some is the determiner. Care was taken to discount repetitions due to dysfluencies in the spoken data as more than one noun phrase. In a small number of cases it was not possible to classify the noun as count singular, count 
plural or non-count, either because the transcriber could not make out the word or the word was in another language - the number marking of which could not be confirmed. There were 4 such instances in the BSAfE corpus, 3 in ICE-EA(K) and 14 in ICE-IND. There was also one case in ICE-EA $(\mathrm{K})$ and two in ICE-IND where the head determined by some was not a common noun, but a cardinal numeral. These cases are not counted as part of the results reported in Table 4, which provides the percentages of determinative some with the aforementioned three types of noun.

Table 4: Distribution of determinative some with different types of nouns (percentage of total occurrences of determinative some) in three WE corpora

\begin{tabular}{|c|c|c|c|c|c|c|c|c|c|}
\hline & \multicolumn{3}{|c|}{ ICE-IND } & \multicolumn{3}{|c|}{ ICE-EA(K) } & \multicolumn{3}{|c|}{ BSAfE } \\
\hline & $\begin{array}{r}\% \\
\text { with } \\
\text { plural } \\
\text { noun }\end{array}$ & $\begin{array}{r}\% \\
\text { with } \\
\text { non- } \\
\text { count } \\
\text { noun } \\
\end{array}$ & $\begin{array}{r}\% \\
\text { with } \\
\text { singu } \\
\text {-lar } \\
\text { noun }\end{array}$ & $\begin{array}{r}\% \\
\text { with } \\
\text { plural } \\
\text { noun }\end{array}$ & $\begin{array}{r}\% \\
\text { with } \\
\text { non- } \\
\text { count } \\
\text { noun }\end{array}$ & $\begin{array}{r}\% \\
\text { with } \\
\text { singu } \\
\text {-lar } \\
\text { noun }\end{array}$ & $\begin{array}{r}\% \\
\text { with } \\
\text { plural } \\
\text { noun }\end{array}$ & $\begin{array}{r}\% \\
\text { with } \\
\text { non- } \\
\text { count } \\
\text { noun }\end{array}$ & $\begin{array}{r}\% \\
\text { with } \\
\text { singu } \\
\text {-lar } \\
\text { noun } \\
\end{array}$ \\
\hline $\begin{array}{l}\text { Interviews and } \\
\text { discussions }\end{array}$ & 49.7 & 24.5 & 25.9 & 57.0 & 15.7 & 27.3 & 56.5 & 21.7 & 21.7 \\
\hline Conversation & 43.8 & 23.9 & 32.3 & 35.9 & 34.8 & 29.3 & 68.1 & 13.1 & 18.8 \\
\hline Classroom lessons & 46.0 & 30.0 & 24.0 & 77.4 & 6.5 & 16.1 & 75.0 & 15.0 & 10.0 \\
\hline Spoken subtotal & 45.2 & 24.5 & 30.3 & 52.5 & 20.7 & 26.8 & 66.2 & 15.6 & 18.2 \\
\hline Student writing & 60.8 & 23.0 & 16.2 & 58.7 & 25.0 & 16.3 & 79.0 & 13.2 & 7.8 \\
\hline Academic writing & 63.4 & 31.7 & 4.9 & 74.3 & 15.0 & 10.6 & 72.0 & 16.0 & 12.0 \\
\hline Journalism & 75.7 & 16.2 & 8.1 & 72.5 & 17.5 & 10.0 & 68.0 & 24.0 & 8.0 \\
\hline Fiction & 27.3 & 47.7 & 25.0 & 41.8 & 52.7 & 5.5 & 33.3 & 22.9 & 43.8 \\
\hline Written subtotal & 57.8 & 29.5 & 12.7 & 63.3 & 25.3 & 11.3 & 71.7 & 15.2 & 13.1 \\
\hline TOTAL & 51.5 & 27.0 & 21.5 & 57.9 & 23.0 & 19.1 & 68.9 & 15.4 & 15.7 \\
\hline
\end{tabular}

There is great variability across the registers within the same corpus and within the same register across corpora. For instance, in the BSAfE corpus, $43.8 \%$ of the occurrences of determinative some in the fiction component occur with singular countable nouns, whereas only $8 \%$ of determinative some in the journalism component and student writing component are headed by singular nouns. In the BSAfE student writing component, $79 \%$ of the instances of determinative some occur with plural nouns. In the student writing components of ICEIND and ICE-EA(K) there are nearly $20 \%$ fewer uses of determinative some with plural nouns $(60.8 \%$ and $58.7 \%$, respectively). This might be due to the high frequency of the noun people in the BSAfE student writing data. In the next section collocation between nouns and determiners will be considered in more detail. The use of some with non-singular (plural + noncount) nouns is significantly higher in the BSAfE student writing data compared to the student writing component of ICE-IND ( $p=0.048$ with Fisher's Exact Test). ${ }^{3}$

It should be pointed out that the hypothesis that some is used as (undeleted) plural marker of indefiniteness arose from a comparison between only the BSAfE student writing subcorpus (in Tables 2 and 3 above) and native English data (Botha 2013). The high frequency of plural nouns after some in the BSAfE written corpus $(71.7 \%)$ is also mainly due to the student

\footnotetext{
${ }^{3}$ Online calculators: http://statpages.org/ctab2x2.html and http://ucrel.lancs.ac.uk/llwizard.html.
} 
writing component. However, the relative frequency of the determiner some is higher in this component of the BSAfE corpus (25.6 per 10000 , cf. Table 2) compared to the other two corpora (18.2 and 23.4 per 10000 , respectively). The percentages for some before plural nouns in the other BSAfE written registers (journalism, academic and fiction) are actually lower than in the corresponding register in at least one of the other two corpora (cf. Table 3). In the spoken registers, the higher frequency of some before plural nouns in the BSAfE corpus is more obvious. Overall, some more frequently determines plural nouns in BSAfE (68.9\%) than in ICE-EA(K) (57.9\%) and both African English corpora have proportionally more instances of some as determiner of plural nouns than ICE-IND (51.5\%).

The quantitative comparison of some as determiner in Indian English, Kenyan English and BSAfE corpora shows a relatively lower frequency of this determiner per 10000 words in the African English corpora compared to Indian English, and that some precedes plural nouns more often in the African English corpora than in the Indian English corpus.

\section{The choice of determiner some in BSAfE registers ${ }^{4}$}

In the previous section it was shown that the determiner some occurs with plural nouns more frequently in the BSAfE corpus. In this section the nouns with which some collocates, and the choice of some from other possible determiners will be investigated in three registers of BSAfE, namely conversation, student writing and professional writing.

Concordances of the word some were drawn from each of the three BSAfE registers. Since the benchmark tagger (CLAWS) tags all instances of some and any with "DD" without distinguishing pronominal uses from determinative (prenominal) uses, concordances of the untagged version of the corpus were manually classified to separate the instances where some is used as determiner from the instances where it is used as a pronoun. Table 5 provides an overview of the raw frequencies of the word some according to its three word class functions.

Table 5: The word some in BSAfE: Raw frequencies

\begin{tabular}{|l|r|r|r|r|r|}
\hline & $\begin{array}{r}\text { Number of } \\
\text { instances of } \\
\text { some as } \\
\text { determiner }\end{array}$ & $\begin{array}{r}\text { Number of } \\
\text { instances of } \\
\text { some in } \\
\text { partitive } \text { of- } \\
\text { construction }\end{array}$ & $\begin{array}{r}\text { Number of } \\
\text { instances of } \\
\text { some as both } \\
\text { logical and } \\
\text { experiential } \\
\text { head of NP }\end{array}$ & $\begin{array}{r}\text { Other } \\
\text { /not pre- } \\
\text { BSAfoninal) }\end{array}$ & $\begin{array}{r}\text { Total } \\
\text { instances of } \\
\text { the word } \\
\text { some }\end{array}$ \\
\hline Conversation & 242 & 89 & 44 & 55 & 430 \\
\hline Student writing & 192 & 91 & 31 & 16 & 330 \\
\hline $\begin{array}{l}\text { Professional } \\
\text { writing }\end{array}$ & 50 & 28 & 5 & 1 & 84 \\
\hline TOTAL & $\mathbf{4 8 4}$ & $\mathbf{2 0 8}$ & $\mathbf{8 0}$ & $\mathbf{7 2}$ & $\mathbf{8 4 4}$ \\
\hline
\end{tabular}

To establish which nouns follow the determiner some most frequently, a collexeme analysis was conducted (Stefanowitsch and Gries 2003, Gries 2014). The concordance lines of some as determiner had to be sifted to identify the noun determined by some in each instance. It was

\footnotetext{
${ }^{4}$ The term "register" is used here in the same sense as it is used by Biber, Johansson, Leech, Conrad and Finegan (1999), i.e. to refer to text types, or "super genres", for instance conversation.
} 
not a matter of simply looking up the word immediately to the right of some, since these could be postdeterminers, numerals, adjectives or classifying nouns, which were ultimately ignored. The table of collocates in the concordance tool of Wordsmith 6.0 is purely positional and counts the amount of times a word occurs in a certain position without regarding the boundaries of grammatical units such as noun phrases. This collocation table (in spreadsheet format) provided a starting point, but had to be carefully checked against the concordance lines. The focus was on only the head element of noun phrases in which some fills the determiner slot. The R-script Coll.analysis 3.5 (Gries 2014) was used to calculate collocational strength based on Fisher-Yates contingency tests between the determiner some and its head nouns (cf. also Stefanowitsch and Gries 2003: 218). To calculate the collocational strength, an input table listing the nouns determined by some, the total number of occurrences of each of these nouns in the register subcorpus, and the number of times each noun occurred as head of a noun phrase in which some is the determiner, had to be prepared. In addition to the input tables for each of the three BSAfE registers, the total number of occurrences of determinative some (cf. the second column of Table 5 above) and an estimate of the total number of noun phrases that could take a determiner had to be provided. This estimate was arrived at by counting all possible common noun tags in a version of the corpus, which was part-of-speech-tagged with CLAWS. The estimated number of potential noun phrases headed by common nouns (and therefore able to take a determiner) for each register is as follows: conversation (21 908), student writing (18 396), professional writing (17 631).

Tables 6, 7 and 8 in the Appendix provide the collostructional strengths between some and nouns for which $p<0.01$, i.e. where the collostructional strength is higher than 2 . The noun with which some collocates most strongly is people ${ }^{5}$ in both the conversation data (see Table 6) and the student writing data (see Table 7). Of the 13 nouns in the conversation data with a collostructional strength higher than 2 (Table 6), 11 are plural nouns: children, places, skills, classes, words, courses, weeks, orders, meetings, families.

In both the writing registers there are uncountable nouns that strongly collocate with the determiner some, most notably the abstract noun extent in the student writing (see Table 7) and degree in the professional writing (see Table 8). In these cases some evokes paucity, and a non-proportional interpretation (in keeping with standard usage), as illustrated in (16) and (17) below.

(16) To some extent poverty is the cause of HIV/AIDS epidemic in the continent. $<$ WXE005> [Student writing]

(17) Property experts say the amendments will protect owners and tenants, and to some degree it will limit the rights of people who illegally occupy land and property. $<\mathrm{W} 2 \mathrm{C}-005\rangle$ [Professional writing]

Of the 11 nouns that strongly collocate with some in the student writing data (Table 7), 7 are plural (instances, colleagues, cases, newspapers, countries, ladies - in addition to people), 2 are uncountable (extent, money), and 2 are singular (distance, animal). Of the 12 nouns with

\footnotetext{
${ }^{5}$ Strictly speaking, the noun people is not inflected for number and can take a plural -s as in the peoples of the African continent. However, people is semantically plural in that it denotes a set of countable entities. It also behaves as a plural noun syntactically in terms of subject-verb agreement. Table 6 also contains the genitive form of the plural noun children. It should be noted that in these cases some children's is a complex possessive determiner in a larger NP, and some is the determiner of the noun children.
} 
which some has a collocational strength higher than 2 in the professional writing data (Table 8), half are plural (cases, financials, staffers, authors, situations, suppliers), 2 are used in an uncountable sense (degree, recourse) and 4 are singular (kind, impetus, way, aspect).

In all three registers, most of the nouns that strongly collocate with some are plural. As was indicated earlier, some is used with particular referents. With plural nouns some typically triggers a proportional interpretation of 'not all', although it can also indicate an unspecified quantity. The question is whether some with plural nouns in the BSAfE corpus is used in these senses, and whether it is used only in these senses. This question will be considered in the light of examples of the some people pattern, since people is the noun that most strongly collocates with the determiner some in both the conversation and student writing data. In examples (18) and (19) below, the underlined noun phrases have particular referents. In example (18), some is used proportionally. In example (19) some denotes an unspecified quantity.

(18) the fact is some people adapt their style and there is this thing that some they don't some do <\#dpc081> [Conversation]

(19) when you go partying and you're at a deep House or like some hectic Hip Hop party, you will bump into some white people in fact a whole lot of them and they'll be into it as much as you are or whatever <Meierkord/Volkswagen: Students2> [Conversation]

Most of the instances of some with plural nouns in the BSAfE data realise the typical (standard) meanings illustrated above. However, there are also instances where some is used in contexts where no determiner would be selected in Standard English. In (20)-(23) below, it is possible to omit the determiner in the underlined noun phrases. The noun people has a nonspecific interpretation in examples (20) and (21) (where it is used in clauses with an irrealis scope) and a generic interpretation in examples (22) and (23), rather than a particular referent.

(20) we need some people some big people as you mention mister xonxa the people who is going to motivate <\#dpc064> [Conversation]

(21) So I think the main solution to reduce the victims of HIV/AIDS is that the government should create more jobs; give free education to some people in rural areas who can't afford and distibute foods and clothes to those who can't afford $<$ TSNO1134> [Student writing]

(22) okay like your friends maybe they are rich and then you are poor and then when when you are going out on on street some people are looking at you and say eyi those boys they are having cool life but this one eyi he is not having cool life <\#dpc159> [Conversation]

(23) I can understand that ja to to you it works because there's a saying that to some people who don't believe in traditional rituals rituals ja ja that that's a waste of money <\#dpc118> [Conversation]

In (20) and (21), ideal (hypothetical) circumstances are described. The speaker/writer is not referring to particular persons, but an unspecified quantity of a certain type of person. This usage context would call for the selection of no overt determiner with the noun people. One might speculate that the "referents" of the noun become cognitively "particular" as the hypothesised circumstances become cognitively "real" in the mind of the speaker/writer. In a qualitative analysis of texts from the Tswana Learner English Corpus, Van Rooy (2008: 351) 
also describes noun phrases in hypothetical situations or events that are developed into "specific entities" by means of determiners and modifiers. The use of some in (22) and (23) seems to be motivated by a need to make the 'not all' implicature of the noun explicit. The determiner some is also used in the generic sense with nouns other than people, as illustrated in (24) below:

(24) so in that question of experience how how do you feel about that because some other bosses might ask you for experience you see how do you feel about the experience issue? <\#dpc141> [Conversation]

Here, some is used with the postdeterminer other, although there is no prior mention of a referent with which the referent of this noun phrase can be contrasted. In a standard English reformulation both words can be omitted. In the conversation data there are 12 instances where some other is used before a noun. There are three such instances of some other $\mathbf{N}$ in the professional writing data and eight in the student writing data. In (25) some could have been omitted, and in (26) other could have been omitted.

(25) they are doing so forced by the requirement to discharge their obligation, which means that there are some other competitive suppliers of the same products elsewhere in the world who are over looked to the benefit of the local $\left.<\mathrm{m}_{\text {_t }} 1000\right\rangle$ [Professional writing]

(26) Now for that matter for instance if some is sick the or she must eat good, adequate food according to sickness because some other diseases are caused by enedequate food <XUE066> [Student writing]

The concordance of some in the conversation component yields several examples with other quantifiers and numerals.

(27) clinically adam lived some nine hundred years after eating from the tree <\#dpc165>

(28) you are good looking but why don't you just go and eh try to have some many friends out there but you i always seeing you going to church <\#dpc191>

(29) like today he just say tomorrow there's gonna be a discrepancy and now some some certain few members should go there see what i mean \#dpc240

(30) Eh she is now (..) two years [(.)] and some couple of months. <Volkswagen>

(31) I think like some few weeks ago <Volkswagen>

(32) sometimes you know take some few kids from the location and get some extra classes there <\#dpc051>

The example in (27) corresponds with the standard use of some with rounded numerals to express an uncertain but considerable quantity. It is not certain whether the single instance of some many, as shown in (28) in the corpus, is an extension of this use or whether it is selfcorrection. In examples (29) to (32) some is used as "plural" of the singulative indefinite article $a$. Although the some few combination is marked in contemporary English, it is not unusual from a diachronic perspective, as the example from a corpus of written White South African English (Wasserman and Van Rooy 2014) illustrates:

(33) When some few days more had elapsed, one morning, shrill screams of pain and terror $\ldots<1850$ s narratives $>$ 
In summary, scrutiny of the concordances of some indicates that its determinative uses in BSAfE largely correspond with Standard English, but that there is evidence of an extension of the usage of some in BSAfE to non-particular contexts. Also, it would seem that the more grammaticalised use of some as plural counterpart of $a$ with the quantifier few seems to continue in BSAfE, whereas it has been discontinued in Standard English varieties. The article-like use of some with other, as plural counterpart of another also suggests that this determiner is more grammaticalised in BSAfE than in Standard English.

Whereas the indefinite article a/an is obligatory before singular countable nouns, some before non-singular nouns is not. To examine the choice of some among other determiners with nonsingular nouns, concordances of five nouns that occurred very frequently in at least two of the BSAfE registers were drawn. This time, the concordances were drawn from the full corpus and no distinction was made between the registers. The nouns of which concordances were drawn are: people, things, women, money and poverty. These nouns were chosen because they are semantically non-singular denoting either sets of countable entities or uncountable concepts, and because they occur frequently enough to allow for potential collocation with a variety of determiners. ${ }^{6}$

The concordance lines of each noun phrase were classified according to the determiner. Some determiners where grouped together as a single type of determiner, e.g. the and such. The word other is conventionally regarded as a special kind of "relative" adjective or as a postdeterminer. In spite of not being a central determiner, the word other is at the same rank as some in contrastive contexts (e.g. some students ... other students), and where it occurred without a definite determiner preceding it, it was classified as a determiner in its own right. Due to the quantificational meanings of some, an argument can also be made that it exists in a choice relationship with numerals and other indefinite quantifiers. Therefore, these were also classified as a type of "determiner" in the concordance data. Table 9 (in the Appendix) provides the raw frequencies of each determiner class used with the selected nouns. Each of these nouns most frequently occurs with the zero determiner. The definite article is the second most frequent determiner with people, money, women and poverty. With the noun things, demonstrative determiners are chosen in a quarter of the instances.

Gries's (2014) Coll.analysis 3.5 R-script was used again to determine the strength of association between a given determiner or determiner type and the five selected nouns. This time a co-varying collexeme analysis was performed and the input table consisted of each concordance line (from all five noun concordances) reduced to only the word in the determiner slot (w1) and the head noun (w2). The construction (c) under investigation is a noun phrase with one of the five chosen non-singular nouns as logico-semantic head. Qualificative modifiers were ignored. Table 10 presents the results restricted only to associations with a strength above 2 (i.e. $\mathrm{p}<0.01$ ). Relations between a determiner and a noun are expressed as attraction (+) or repulsion (-).

The high level of attraction between some and people is confirmed in the co-varying collexeme analysis (collocational strength $=6.66$ ). The determiner some does not have a significantly strong association with any of the other four nouns under investigation. The noun people is also

\footnotetext{
${ }^{6}$ Only a few nouns were selected to check whether some is preferred over the zero determiner with nouns with nonsingular meaning. Ideally, all nouns and all determiners in a corpus could be used to provide a full collexeme analysis; however, this would be a time-consuming task that falls outside the scope of the current study.
} 
positively associated with other (collocational strength $=4.99$ ). Demonstrative and quantifying determiners are also strongly attracted to the noun people. There is a strong negative association (i.e. repulsion) between the zero determiner and people, given the frequency of this noun and the frequency of the zero determiner with the other nouns under investigation, despite the fact that the zero determiner is the single determiner most frequently occurring with people (as can be seen in Table 9). The zero determiner also has a strong negative association with the plural noun things (8.47) and with the concrete uncountable noun money (2.33), but a strong positive association with the abstract uncountable noun poverty (120.88) and the concrete countable noun women (2.76). The repulsion between the zero determiner and things, between the zero determiner and money, and between demonstratives and money is interesting in the light of the attraction between demonstratives and things, and between possessives and money. Inclusion of more nouns in the co-varying collexeme analysis would shed more light on determiner choice in the corpus. However, for the purposes of this investigation, the data analysis is sufficient to illustrate contexts in which some is preferred over the zero determiner in BSAfE. Performing similar collexeme analyses on corpora of other varieties of English will help determine to which extent determiner choice phenomena are specific to BSAfE. Such comparison warrants future investigation.

\section{Conclusion}

This study has attempted to move beyond the listing of uses of the determiner some in BSAfE with words it is incompatible with in contemporary standard English, such as few and certain, and to explore the possibility that the core meaning of some ('particular, unspecified quantity') is extended to more grammatical uses in BSAfE. In the case of wider usage potential one would expect higher frequency, but a comparison of the BSAfE data with two other varieties (Indian English and Kenyan English) shows that the determiner some is significantly less frequent in both African corpora compared with the Indian English corpus. However, some is more frequently a determiner of plural nouns in the BSAfE corpus compared with the other two corpora.

The nouns with which the determiner some most strongly collocates in the BSAfE corpus are mostly plural nouns. Among these collocations with plural nouns, evidence of the extended, grammaticalised use of this determiner with plural nouns can be found. However, the corpus is very small, and therefore the data too sparse, to make any quantitative claims about the extended usage of determinative some in BSAfE.

A co-varying collexeme analysis considering all possible determiner-slot fillers in relation to five very frequent nouns in the corpus shows large collocational strength between the zero determiner and plural nouns, but this association is negative in the case of the nouns things and people. The strong attraction between the plural noun people and the determiner some is confirmed in the co-varying collexeme analysis. It may well be that other varieties of English show similar attractions between some and people, or between certain other nouns and determiners, and further investigations into conventionalised choices of certain determiners with certain nouns are necessary. ${ }^{7}$

The qualitative and quantitative evidence suggests that most so-called "non-standard" uses of the determiner some can be explained in terms of an extension of the core meaning of some in

\footnotetext{
${ }^{7} \mathrm{I}$ am indebted to the reviewer who pointed this out.
} 
all three registers of BSAfE under investigation, but the quantitative data is not large enough to argue conclusively for a more advanced grammaticalisation of some in BSAfE, and evidence of this in the professional writing component is especially scarce. The scarcity of evidence in the professional writing component may partly be due to editorial intervention in which case it is not truly conventionalised and may be restricted to informal contexts (Kruger and Van Rooy under revision). However, the professional writing component in this study was very small and further investigation of larger bodies of professional writing is needed to establish the extent to which the article-like use of some is accepted in contexts where it might be omitted.

\section{References}

Biber, D., S. Johansson, G. Leech, S. Conrad and E. Finegan. 1999. Longman grammar of spoken and written English. Essex: Longman.

Botha, Y. 2012. Specification in the English Nominal Group with Reference to Student Writing. Unpublished doctoral thesis, North-West University.

Botha, Y. 2013. Corpus evidence of anti-deletion in Black South African English noun phrases. English Today 29(1): 16-21.

Coetzee-Van Rooy, A.S. 2012. Flourishing functional multilingualism: Evidence from language repertoires in the Vaal Triangle region. International Journal of the Sociology of Language 218: 87-119.

De Klerk, V. 2003a. Xhosa English as an institutionalised variety of English: In search of evidence. English World-Wide 24(2): 221-243.

De Klerk, V. 2003b. Towards a norm in South African Englishes: The case for Xhosa English. World Englishes 22(4): 463-481.

Duffley, P.J. and P. Larrivée. 2012. Exploring the relation between the qualitative and quantitative uses of the determiner some. English Language and Linguistics 16(1): 131-149.

Granger, S., E. Dagneaux, F. Meunier and M. Paquot. (Eds.) 2009. International Corpus of Learner English Version 2. Louvain: UCL Presses Universitaires de Louvain.

Gries, S.Th. 2014. Coll.analysis 3.5. A script for R to perform collostructional analysis.

Kachru, B. 1986. The alchemy of English. Oxford: Pergamon.

Kruger, H. and B. van Rooy. (under revision) Editorial practice and the distinction between error and conventionalised innovation in New Englishes: The progressive in Black South African English. World Englishes.

Makalela, L. 2004. Making sense of BSAE for linguistic democracy in South Africa. World Englishes 23(3): 355-366. 
Meierkord, C. 2012. Interactions across Englishes: Linguistic choices in local and international contexts. Cambridge: Cambridge University Press.

Mesthrie, R. 2006. Anti-deletions in an L2 grammar: A study of Black South African English mesolect. English World-Wide 27: 111-145.

Minow, V. 2010. Variation in the grammar of Black South African English. Frankfurt am Main: Peter Lang.

Mukherjee, J. 2010. The English language in India. In A. Kirkpatrick. (Ed.) The Routledge handbook of world Englishes. London: Routledge. pp. 167-180.

Mukherjee, J. and S. Hoffman. 2006. Describing verb-complementational profiles of New Englishes: A pilot study of Indian English. English World-Wide 27: 147-173.

Payne, J. and R. Huddleston. 2002. Nouns and noun phrases. In R. Huddleston and G.K. Pullum. (Eds.) The Cambridge grammar of the English language. Cambridge: Cambridge University Press. pp. 323-524.

Platt, J., H. Weber and M.L. Ho. 1984. The new Englishes. London: Routledge and Kegan Paul.

Schmied, J. 1990. Corpus linguistics and non-native varieties of English. World Englishes 9: 255-268.

Scott, M. 2013. Wordsmith Tools manual: version 6.0. Liverpool: Lexical Analysis Software.

Stefanowitsch, A. and S.Th. Gries. 2003. Collostructions: Investigating the interaction of words and constructions. International Journal of Corpus Linguistics 8(2): 209-243.

Van der Walt, J.L. and B. van Rooy. 2002. Towards a norm in South African Englishes. World Englishes 21(1): 113-128.

Van Rooy, B. 2008. An alternative interpretation of tense and aspect in Black South African English. World Englishes 27(3/4): 335-358.

Van Rooy, B. 2010. Social and linguistic perspectives on variability in World Englishes. World Englishes 29(10): 3-20.

Van Rooy, B. 2014. Progressive aspect and stative verbs in Outer Circle varieties. World Englishes 33(2): 157-172.

Wasserman, R. and B. van Rooy. 2014. The development of modals of obligation and necessity in White South African English through contact with Afrikaans. Journal of English Linguistics 42(1): 31-50.

Zerbian, S. 2015. Syntactic and prosodic focus marking in contact varieties of South African English. English World-Wide 36(2): 228-258. 


\section{APPENDIX}

Table 6: Collostructional strength of nouns with determiner some in BSAfE Conversation ${ }^{8}$

\begin{tabular}{|l|r|r|r|}
\hline Noun & $\begin{array}{r}\text { Frequency in } \\
\text { subcorpus }\end{array}$ & $\begin{array}{r}\text { Number of } \\
\text { occurrences with } \\
\text { determiner some }\end{array}$ & $\begin{array}{r}\text { Collocational } \\
\text { strength }\end{array}$ \\
\hline people & 1068 & 34 & 7.55 \\
\hline children's & 3 & 3 & 5.88 \\
\hline places & 39 & 6 & 5.39 \\
\hline skills & 15 & 4 & 4.74 \\
\hline classes & 12 & 3 & 3.57 \\
\hline words & 52 & 5 & 3.57 \\
\hline courses & 3 & 2 & 3.44 \\
\hline weeks & 15 & 3 & 3.26 \\
\hline orders & 5 & 2 & 2.92 \\
\hline meetings & 7 & 2 & 2.61 \\
\hline reason & 32 & 3 & 2.28 \\
\hline place & 144 & 6 & 2.27 \\
\hline families & 12 & 2 & 2.13 \\
\hline
\end{tabular}

Table 7: Collostructional strength of nouns with determiner some in BSAfE Student Writing

\begin{tabular}{|l|r|r|r|}
\hline Noun & $\begin{array}{r}\text { Frequency in } \\
\text { subcorpus }\end{array}$ & $\begin{array}{r}\text { Number of } \\
\text { occurrences with } \\
\text { determiner some }\end{array}$ & $\begin{array}{r}\text { Collocational } \\
\text { strength }\end{array}$ \\
\hline people & 1049 & 48 & 17.89 \\
\hline extent & 9 & 6 & 10.01 \\
\hline instances & 5 & 3 & 4.96 \\
\hline colleagues & 3 & 2 & 3.49 \\
\hline cases & 32 & 4 & 3.48 \\
\hline distance & 5 & 2 & 2.97 \\
\hline animal & 6 & 2 & 2.8 \\
\hline newspapers & 8 & 2 & 2.54 \\
\hline money & 257 & 8 & 2.25 \\
\hline countries & 162 & 6 & 2.15 \\
\hline ladies & 13 & 2 & 2.11 \\
\hline
\end{tabular}

\footnotetext{
${ }^{8} \mathrm{p}<0.001$ where collocational strength $>3$ and $\mathrm{p}<0.01$ where collocational strength $>2$.

${ }^{9}$ In Tables 6, 7 and 8, nouns that are semantically plural are in bold, and uncountable nouns are in italics. Also see Footnote 5 regarding the morphology of these nouns.
} 
Table 8: Collostructional strength of nouns with determiner some in BSAfE Professional Writing

\begin{tabular}{|l|r|r|r|}
\hline Noun & $\begin{array}{r}\text { Frequency in } \\
\text { subcorpus }\end{array}$ & $\begin{array}{r}\text { Number of } \\
\text { occurrences with } \\
\text { determiner some }\end{array}$ & $\begin{array}{r}\text { Collocational } \\
\text { strength }\end{array}$ \\
\hline cases & 20 & 3 & 4.63 \\
\hline degree & 7 & 2 & 3.79 \\
\hline kind & 11 & 2 & 3.37 \\
\hline financials & 1 & 1 & 2.55 \\
\hline staffers & 1 & 1 & 2.55 \\
\hline impetus & 2 & 1 & 2.25 \\
\hline recourse & 2 & 1 & 2.25 \\
\hline way & 42 & 2 & 2.2 \\
\hline aspect & 3 & 1 & 2.07 \\
\hline authors & 3 & 1 & 2.07 \\
\hline situations & 3 & 1 & 2.07 \\
\hline suppliers & 3 & 1 & 2.07 \\
\hline
\end{tabular}

Table 9: Raw frequencies of determiner (types) with five non-singular nouns in BSAfE corpus

\begin{tabular}{|l|r|r|r|r|r|r|}
\hline & \multicolumn{7}{|c|}{ Total per noun across all three registers } & \\
\cline { 2 - 6 } & people & money & things & women & poverty & \\
\hline alan/no & 11 & 23 & 2 & 2 & 4 & $\mathbf{4 2}$ \\
\hline both & 1 & 0 & 0 & 0 & 0 & $\mathbf{1}$ \\
\hline Demonstratives & 194 & 23 & 129 & 23 & 13 & $\mathbf{3 8 2}$ \\
\hline we/us/you & 8 & 0 & 0 & 0 & 0 & $\mathbf{8}$ \\
\hline Quantifiers/Numerals & 197 & 42 & 35 & 17 & 3 & $\mathbf{2 9 4}$ \\
\hline other & 64 & 0 & 19 & 4 & 0 & $\mathbf{8 7}$ \\
\hline Possessives & 45 & 32 & 16 & 1 & 3 & $\mathbf{9 7}$ \\
\hline some & 82 & 12 & 11 & 5 & 0 & $\mathbf{1 1 0}$ \\
\hline the/such & 434 & 85 & 68 & 23 & 22 & $\mathbf{6 3 2}$ \\
\hline all & 12 & 0 & 2 & 0 & 0 & $\mathbf{1 4}$ \\
\hline any & 2 & 1 & 1 & 0 & 0 & $\mathbf{4}$ \\
\hline$\varnothing$ & 1179 & 277 & 231 & 192 & 752 & $\mathbf{2 6 3 1}$ \\
\hline certain/exact/specific & 1 & 0 & 9 & 0 & 0 & $\mathbf{1 0}$ \\
\hline Totals & $\mathbf{2 2 3 0}$ & $\mathbf{4 9 5}$ & $\mathbf{5 2 3}$ & $\mathbf{2 6 7}$ & $\mathbf{7 9 7}$ & $\mathbf{4 3 1 2}$ \\
\hline
\end{tabular}


Table 10: Collostructional strength between determiners and selected nouns

\begin{tabular}{|c|c|c|c|c|c|c|c|c|c|}
\hline & $\begin{array}{l}\mathrm{w} 2= \\
\text { noun }\end{array}$ & $\begin{array}{r}\text { freq } \\
\text { w1 }\end{array}$ & $\begin{array}{r}\text { freq } \\
\text { w2 }\end{array}$ & $\begin{array}{r}\text { obs. } \\
\text { w1_w2 } \\
\text { in_NP }\end{array}$ & $\begin{array}{r}\text { exp. } \\
\text { w1_w2 } \\
\text { in_NP }\end{array}$ & & $\begin{array}{r}\text { delta.p } \\
\text { constr } \\
\text { to } \\
\text { word }\end{array}$ & $\begin{array}{r}\text { delta.p } \\
\text { word } \\
\text { to } \\
\text { constr }\end{array}$ & $\begin{array}{l}\text { Colloca- } \\
\text { tional } \\
\text { strength }\end{array}$ \\
\hline$\varnothing$ & poverty & 2701 & 797 & 752 & 489.69 & + & 0.25 & 0.4 & 120.88 \\
\hline Demonstratives & things & 382 & 596 & 129 & 51.79 & + & 0.22 & 0.15 & 25.92 \\
\hline the/such & people & 632 & 2233 & 434 & 321.03 & + & 0.21 & 0.1 & 22.16 \\
\hline alan/no & money & 42 & 495 & 23 & 4.73 & + & 0.44 & 0.04 & 11.27 \\
\hline $\begin{array}{l}\text { Quantifiers/ } \\
\text { Numerals }\end{array}$ & people & 294 & 2233 & 197 & 149.34 & + & 0.17 & 0.04 & 8.35 \\
\hline Possessives & money & 97 & 495 & 32 & 10.92 & + & 0.22 & 0.05 & 8.17 \\
\hline some & people & 110 & 2233 & 82 & 55.88 & + & 0.24 & 0.02 & 6.66 \\
\hline other & people & 87 & 2233 & 64 & 44.19 & + & 0.23 & 0.02 & 4.99 \\
\hline$\varnothing$ & women & 2701 & 275 & 192 & 168.97 & + & 0.02 & 0.09 & 2.76 \\
\hline$\varnothing$ & people & 2701 & 2233 & 1179 & 1372 & - & -0.19 & -0.18 & 32.63 \\
\hline thelsuch & poverty & 632 & 797 & 22 & 114.58 & - & -0.17 & -0.14 & 32.05 \\
\hline $\begin{array}{l}\text { Quantifiers/ } \\
\text { Numerals }\end{array}$ & poverty & 294 & 797 & 3 & 53.3 & - & -0.18 & -0.08 & 21.75 \\
\hline Demonstratives & poverty & 382 & 797 & 13 & 69.26 & - & -0.16 & -0.09 & 19.07 \\
\hline$\varnothing$ & things & 2701 & 596 & 301 & 366.2 & - & -0.06 & -0.13 & 8.47 \\
\hline Possessives & poverty & 97 & 797 & 3 & 17.59 & - & -0.15 & -0.02 & 5.23 \\
\hline Demonstratives & money & 382 & 495 & 23 & 43.01 & - & -0.06 & -0.05 & 3.69 \\
\hline alan/no & people & 42 & 2233 & 11 & 21.33 & - & -0.25 & -0.01 & 3.01 \\
\hline the/such & women & 632 & 275 & 23 & 39.54 & - & -0.03 & -0.06 & 2.89 \\
\hline$\varnothing$ & money & 2701 & 495 & 277 & 304.14 & - & -0.03 & -0.06 & 2.33 \\
\hline
\end{tabular}

